\title{
Tumor Targeting of MMP-2/9 Activatable Cell-Penetrating Imaging Probes Is Caused by Tumor-Independent Activation
}

\author{
Sander M.J. van Duijnhoven ${ }^{1}$, Marc S. Robillard ${ }^{2}$, Klaas Nicolay ${ }^{1}$, and Holger Grüll ${ }^{1,2}$ \\ ${ }^{1}$ Department of Biomedical Engineering, Eindhoven University of Technology, Eindhoven, The Netherlands; and ${ }^{2}$ Department of \\ Biomolecular Engineering, Philips Research, Eindhoven, The Netherlands
}

Activatable cell-penetrating peptides (ACPPs) are a new class of promising molecular imaging probes for the visualization of enzymes in vivo. The cell-penetrating function of a polycationic peptide is efficiently blocked by intramolecular electrostatic interactions with a polyanionic peptide. Proteolysis of a cleavable linker present between the polycationic cell-penetrating peptide and polyanionic peptide affords dissociation of both domains and enables the activated cell-penetrating peptide to enter cells. Here, we aimed to develop an ACPP sensitive to matrix metalloproteinase-2 and -9 (MMP-2/9) for nuclear imaging purposes. Methods: MMP-2/9 ACPPs and nonactivatable cell-penetrating peptides (non-ACPP) were prepared by 9 fluorenylmethyloxycarbonyl solid-phase peptide synthesis and labeled with ${ }^{177} \mathrm{Lu}$ or ${ }^{177} \mathrm{Lu} /{ }^{125}$ I for dual-isotope studies. The in vivo biodistribution of these probes was assessed in MMP-2/9positive tumor-bearing mice $(n=6)$ and healthy mice $(n=4)$ using $\gamma$-counting. Furthermore, a radiolabeled cell-penetrating peptide serving as a positive control was evaluated in tumorbearing mice $(n=6)$. Results: Biodistribution studies showed a 5 -fold-higher retention of ACPP in tumor than in muscle $(P<$ $0.01)$ and a 6 -fold-higher tumor retention relative to non-ACPP $(P<0.01)$, supporting earlier studies on fluorescently labeled ACPPs proposing activation by tumor-associated MMP-2/9. Surprisingly, however, the uptake of ACPP was significantly higher than that of non-ACPP in almost all tissues $(P<0.01)$. To unravel the activation process of ACPP in vivo, we developed dual-isotope ACPP analogs (dACPPs) that allowed us to discriminate between uncleaved dACPP and activated dACPP. In vivo biodistribution of dACPP indicated that the tissue-associated counts originated from activated dACPP. Interestingly, dACPP administration to healthy mice, compared with MMP2/9-positive tumor-bearing mice, resulted in a similar dACPP biodistribution. Furthermore, a radiolabeled cell-penetrating peptide showed tumor-to-tissue ratios equal to those found for ACPP $(P>0.05)$. Conclusion: This study demonstrates that the tumor targeting of radiolabeled MMP-2/9 ACPPs is most likely caused by the activation in the vascular compartment rather than tumor-specific activation, as suggested earlier. The results in the present paper indicate that different and more tissue-specific enzyme-ACPP combinations are needed to unleash the full potential of the elegant ACPP concept in living animals.

Received Aug. 19, 2010; revision accepted Oct. 19, 2010.

For correspondence or reprints contact: Holger Grüll, Philips Research,

HTC 11, 5656AE Eindhoven, The Netherlands.

E-mail: holger.gruell@philips.com

COPYRIGHT @ 2011 by the Society of Nuclear Medicine, Inc.
Key Words: molecular imaging; cancer; activatable cell penetrating peptide; dual-isotope; matrix metalloproteinase

J Nucl Med 2011; 52:279-286

DOI: 10.2967/jnumed.110.082503

\section{$\mathbf{T}$} he family of matrix metalloproteinases (MMPs) has been identified as a key modulator in extracellular matrix remodeling, which is a hallmark of pathologic conditions such as cancer, atherosclerosis, and heart failure (1-4). The recognition of MMPs as disease biomarkers has stimulated the development of imaging strategies targeting these proteases, aiming for improved diagnosis or application in image-guided surgery. Commonly used approaches for MMP imaging are based on targeting with antibodies or smallmolecule ligands (5-9). For example, radiolabeled MMP binding ligands have been developed for the detection of upregulated MMP levels by means of SPECT or PET (1012). Other strategies for MMP imaging, which do take full advantage of the nature of the target, are directed at the activity of the enzyme and will provide a selective readout of the activated MMP subpopulation and, importantly, lead to signal amplification because a single MMP can continuously activate its substrate (13). Recently, a variety of substrate-flanked fluorescence resonance energy-transfer probes has been developed to sense MMP activity in living organisms (14-18). Typically, these smart probes consist of one or multiple intramolecularly quenched fluorophores that become fluorescent on activation. With the exception of optical-guided interventions, these probes are unfortunately of limited clinical use for general imaging-based diagnostics.

Other protease-activatable imaging strategies that are not restricted to any one imaging modality have used probes that accumulated in MMP-rich tissue by hydrophobic clustering, cellular tagging, or cellular penetration on activation by MMP (19-21). The latter strategy centered on an activatable cell-penetrating peptide (ACPP) that consisted of a matrix metalloproteinase-2 and -9 (MMP-2/9) substrate inserted between a polyanionic peptide and polycationic cell-penetrating peptide (CPP) conjugated to an imaging label. The cell-penetrating property of the polycationic peptide was quenched by electrostatic interactions with the polyanionic 
domain, preventing cellular uptake of the probe (22). Cleavage of the substrate by MMP-2/9 released the polycationic from the polyanionic domain, thereby triggering cellular adhesion and subsequent uptake of the imaging label-functionalized polycationic peptide. A 3- to 4-fold increase in tumor homing was observed for ACPPs, compared with MMP-2/9 uncleavable control peptides, accompanied by a 4-fold-higher ACPP retention in tumor than in muscle (2123). Although ACPPs were successfully used for optical imaging and MRI of MMP-2/9 (21-25), the use of this concept in nuclear imaging or therapy has remained largely unexplored. Recently Watkins et al. investigated an MMP14-activatable analog for SPECT (26). Although in vitro activation was observed in cell cultures expressing MMP14, a control cell line lacking MMP-14 expression also activated the probe, and therefore MMP-14 selectivity could not be demonstrated. In this work, we explored the use of radiolabeled ACPPs (Fig. 1A) for later application in SPECT or potentially PET of MMP-2/9 expression in tumors. The MMP-2/9-selective sequence in our study was used earlier by Jiang et al. (21). The polycationic and polyanionic domains consisted of D-amino acids to avoid proteolytic degradation of these domains. The CPP domain of ACPP was functionalized with a DOTA chelate and radiolabeled with ${ }^{177} \mathrm{Lu}$. The ACPP was then studied in vitro in MMP-2/ 9-positive HT-1080 fibrosarcoma cell cultures and in vivo in HT-1080 tumor-bearing mice together with a ${ }^{177} \mathrm{Lu}-$ radiolabeled nonactivatable CPP (non-ACPP) serving as a negative control and CPP without the polyanionic domain as a positive control (Fig. 1B). For further insights into the mode of action of ACPP, we also developed dual-isotopelabeled analogs for the MMP activatable and nonactivatable probes (dACPP and non-dACPP, respectively) (Fig. 1B). The dual-isotope approach allowed us to discriminate between activated ACPP and uncleaved ACPP as well as aspecific tissue uptake of the negative control in healthy and tumor-bearing mice.

\section{MATERIALS AND METHODS}

\section{Materials}

All reagents and solvents were obtained from commercial sources (Sigma-Aldrich and Biosolve) and used without further purification. 9-fluorenylmethyloxycarbonyl-protected amino acids and Rink amide resin were purchased from either Novabiochem (Merck) or Bachem. DOTA succinimidyl ester was obtained from Macrocyclics. Human recombinant enzymes were purchased from Calbiochem (Merck), Sigma, or R\&D Systems. The enzymes were activated according to the vendor's protocols if needed. The labeling buffers were treated with Chelex-100 resin (BioRad Laboratories) overnight and passed through a $0.22-\mu \mathrm{m}$ filter. IODO-GEN iodination tubes were purchased from Pierce Protein Research (Thermo Fischer Scientific). Tablets to prepare phosphate-buffered saline (PBS) ( $\mathrm{pH}$ 7.4) were acquired from Calbiochem (Merck).

\section{Probe Synthesis}

Peptides Ac- $\mathrm{e}_{9}-x$-PLGLAG- $\mathrm{r}_{9}-x$-k(Mtt)-resin, Ac- $\mathrm{e}_{9}-x$-LALGPG$\mathrm{r}_{9^{-}}-\mathrm{k}$-k(Mtt)-resin, Ac-y-e ${ }^{-} x$-PLGLAG- $\mathrm{r}_{9}-x-\mathrm{k}(\mathrm{Mtt})-\mathrm{resin}, \quad$ Ac- $-\mathrm{e}_{9^{-}}$ $x$-LALGPG-r ${ }_{9}-x$-k(Mtt)-resin, and Ac-LAG- ${ }_{9}-x$-k(Mtt)-resin were synthesized on an automatic synthesizer (Prelude; Protein Technologies Inc.) by 9-fluorenylmethyloxycarbonyl solid-phase peptide synthesis using Rink amide resin $(0.1 \mathrm{mmol}), 2-(1 \mathrm{H}-$ benzotriazole1-yl)-1,1,3,3-tetramethyluronium hexafluorophosphate as the activating reagent, and $\mathrm{N}, \mathrm{N}$-diisopropylethylamine as a base. D-amino acids are denoted in lower case and $x$ represents 6-aminohexanoic acid. The Mtt protecting group was selectively removed by incubating the peptides on resin with $1.8 \% \mathrm{v} / \mathrm{v}$ trifluoroacetic acid in dichloromethane with $2.0 \% \mathrm{v} / \mathrm{v}$ triisopropylsilane as a scavenger for $10 \times$ $3 \mathrm{~min}$, after which DOTA succinimidyl ester (1.5 equivalents) in $\mathrm{N}$-methylpyrrolidone was added to the peptide resins and reacted overnight in the presence of $N, N$-diisopropylethylamine. The peptides were cleaved from the resin using a mixture of $96.0 \% \mathrm{v} / \mathrm{v}$
FIGURE 1. Mechanism and structure of radiolabeled MMP-2/9 activatable ACPPs. (A) Cell-penetrating property of polycationic peptide is masked by polyanionic peptide. Cleavage of linker by MMP-2/9 releases polycationic CPP, which will transfer its radionuclide cargo across cell membrane. Trapped radioactivity can be imaged by SPECT or PET. Figure adapted from Jiang et al. (21). (B) Peptide structure of MMP-2/9 sensitive ${ }^{177} \mathrm{Lu}-\mathrm{ACPP}$ (i), negative-control ${ }^{177}$ Lu-non-ACPP containing scrambled linker (ii), positive-control ${ }^{177} \mathrm{Lu}$-CPP (iii), MMP-2/9-sensitive dual-isotope-radiolabeled ${ }^{177} \mathrm{Lu} /{ }^{125}$-dACPP (iv), and negativecontrol ${ }^{177} \mathrm{Lu} /{ }^{125}$ I-non-dACPP (v). MMP-2/9 will cleave linker of ACPP between glycine and leucine residue. $X$ denotes amino-hexanoic acid. Lowercase letters indicate Damino acids.

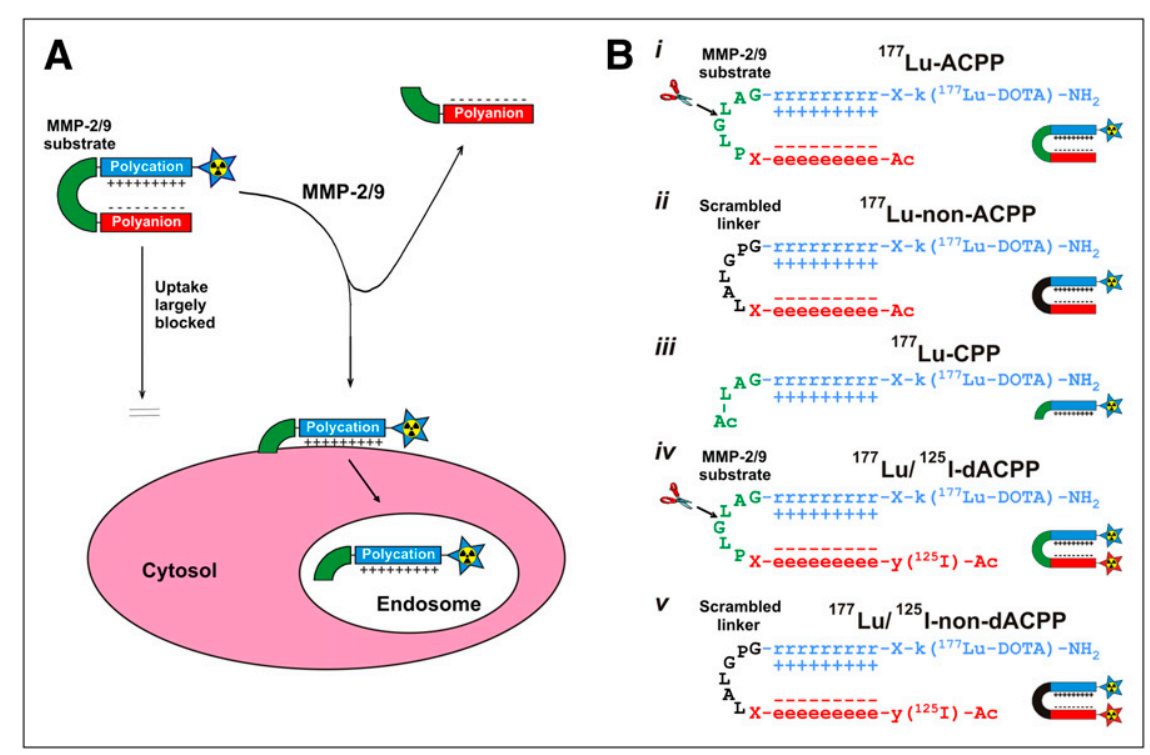


trifluoroacetic acid, $2.0 \% \mathrm{v} / \mathrm{v}$ triisopropylsilane, and 2.0\% v/v MilliQ (Millipore) water for $4 \mathrm{~h}$; filtered; and precipitated in ice-cold diethylether. The peptide pellets were dissolved in MilliQ water and purified by preparative reversed-phase high-pressure liquid chromatography (HPLC) using an Agilent 1200 apparatus, equipped with a C18 Zorbax column $(150 \times 21.2 \mathrm{~mm}$; particle size, $5.0 \mu \mathrm{m})$. The ultraviolet wavelength was preset at 210 and $254 \mathrm{~nm}$. All peptide structures were analyzed by liquid chromatography-mass spectroscopy (LC-MS) on an Agilent 1200 apparatus, equipped with a C18 Eclipse plus column $(100 \times 2.1 \mathrm{~mm}$; particle size, $3.5 \mu \mathrm{m})$ and an electrospray mass spectrometer (model 6210 [Agilent Technologies], time-of-flight LC-MS) (Supplemental Fig. 1; supplemental materials are available online only at http://jnm.snmjournals.org). Found masses: 3,874.1 Da for Ac- $\mathrm{e}_{9}-x$-PLGLAG- $\mathrm{r}_{9}-x$-k(DOTA)- $\mathrm{NH}_{2}$ (ACPP, calculated, 3,874.1 Da), 3,874.1 Da for Ac-e ${ }_{9}-x$-LALGPG- $\mathrm{r}_{9}-x$-k(DOTA)$\mathrm{NH}_{2}$ (non-ACPP, calculated, 3,874.1), 4,037.2 Da for Ac-y-e $e_{9}-x-$ PLGLAG- $\mathrm{r}_{9}-x$-k(DOTA)- $\mathrm{NH}_{2}$ (dACPP, calculated, 4,037.1 Da), 4,037.2 Da for Ac-y-e ${ }_{9}-x$-LALGPG- ${ }_{9}-x$-k(DOTA)- $\mathrm{NH}_{2}$ (nondACPP, calculated, 4,037.1 Da), and 2,332.5 Da for Ac-LAG-r $9^{-}$ $x$-k(DOTA)- $\mathrm{NH}_{2}$ (CPP, calculated, 2,332.4 Da).

\section{Enzyme ACCP Cleavage Assay}

dACPP or non-ACPP $(0.1 \mathrm{mM})$ was incubated in triplicate with 5 nM human-recombinant MMP-1, MMP-2, MMP-3, MMP-7, MMP-9, MMP-14, thrombin, plasmin, or urokinase in a mixture of $50 \mathrm{mM}$ Tris, $200 \mathrm{mM} \mathrm{NaCl}, 10 \mathrm{mM} \mathrm{CaCl}_{2}$, and $10 \mu \mathrm{M} \mathrm{ZnCl}_{2}$ at $\mathrm{pH} 7.5$ at 700 revolutions per minute (rpm) and $37^{\circ} \mathrm{C}$. After $1 \mathrm{~h}$, the enzymes were quenched by the addition of trifluoroacetic acid $(10 \% \mathrm{v} / \mathrm{v})$. To determine the percentage cleaved peptide, the formation of the activated CPP domain was monitored by LC-MS and compared with a $100 \%$ cleaved reference sample $(0.1 \mathrm{mM}$ dACPP incubated with $30 \mathrm{nM}$ MMP-2 for $1 \mathrm{~h}$ ).

\section{Animal Studies}

All animal procedures were approved by the ethical review committee of the Maastricht University Hospital (The Netherlands) and were performed according to the principles of laboratory animal care (27) and the Dutch national law "Wet op Dierproeven" (Stb 1985, 336). Six-week-old athymic female mice (CD-1 nu/nu; body weight, 22-30 g; Charles River Laboratories) were housed in an enriched environment under standard conditions: $23^{\circ} \mathrm{C}-25^{\circ} \mathrm{C}, 50 \%-60 \%$ humidity, and 12 -h light-dark cycles for more than $1 \mathrm{wk}$. Food and water were freely available.

\section{Radiolabeling}

For In Vitro Cell Assay. ${ }^{177} \mathrm{LuCl}_{3}$ (PerkinElmer) in $0.05 \mathrm{M} \mathrm{HCl}$ (20.0 $\mu \mathrm{L}, 10.0 \mathrm{MBq}$ ) was mixed with ACPP, non-ACPP, or CPP in MilliQ water $(33.4 \mu \mathrm{L}, 25.8 \mathrm{nmol})$ and $0.2 \mathrm{M}$ Tris- $\mathrm{HCl}$ at $\mathrm{pH} 7.4$ $(346 \mu \mathrm{L})$ for $20 \mathrm{~min}$ at $300 \mathrm{rpm}$ and $90^{\circ} \mathrm{C}$.

For In Vivo Studies. For ${ }^{177} \mathrm{Lu}-\mathrm{ACPP}$ and ${ }^{177} \mathrm{Lu}-\mathrm{non}-\mathrm{ACPP}$, ${ }^{177} \mathrm{LuCl}_{3}$ in $0.05 \mathrm{M} \mathrm{HCl}(5.0 \mu \mathrm{L}, 5.0 \mathrm{MBq})$ was mixed with ACPP or non-ACPP in MilliQ water $(38.8 \mu \mathrm{L}, 300 \mathrm{nmol})$ and metal-free $0.9 \% \mathrm{NaCl}(450 \mu \mathrm{L})$ for $20 \mathrm{~min}$ at $300 \mathrm{rpm}$ and $90^{\circ} \mathrm{C}$. For ${ }^{177} \mathrm{Lu} /{ }^{125} \mathrm{I}-\mathrm{dACPP}$ and ${ }^{177} \mathrm{Lu} /{ }^{125} \mathrm{I}$-non-dACPP, ${ }^{177} \mathrm{LuCl}_{3}$ in $0.05 \mathrm{M}$ $\mathrm{HCl}(5.0 \mu \mathrm{L}, 10.0 \mathrm{MBq})$ was mixed with dACPP or non-dACPP in MilliQ water $(38.8 \mu \mathrm{L}, 300 \mathrm{nmol})$ and metal-free $0.9 \% \mathrm{NaCl}(450$ $\mu \mathrm{L}$ ) for $20 \mathrm{~min}$ at $300 \mathrm{rpm}$ and $90^{\circ} \mathrm{C} .{ }^{125} \mathrm{I}$ (PerkinElmer) in $1 \mathrm{mM}$ $\mathrm{NaOH}(5.0 \mu \mathrm{L}, 2.5 \mathrm{MBq})$ was mixed with dACPP or non-dACPP in MilliQ water $(38.8 \mu \mathrm{L}, 300 \mathrm{nmol})$ and PBS $(225 \mu \mathrm{L})$ in an IODOGEN iodination tube for $7 \mathrm{~min}$ at $300 \mathrm{rpm}$ and $25^{\circ} \mathrm{C}$ and transferred to a siliconized $1.5-\mathrm{mL}$ tube together with $250 \mu \mathrm{L}$ of $0.9 \% \mathrm{NaCl}$. For ${ }^{177} \mathrm{Lu}-\mathrm{CPP},{ }^{177} \mathrm{LuCl}_{3}$ in $0.05 \mathrm{M} \mathrm{HCl}(5.0 \mu \mathrm{L}, 5.0 \mathrm{MBq})$ was mixed with CPP in MilliQ water $(31.5 \mu \mathrm{L}, 300 \mathrm{nmol})$ and metalfree $0.9 \% \mathrm{NaCl}(450 \mu \mathrm{L})$ for $20 \mathrm{~min}$ at $300 \mathrm{rpm}$ and $90^{\circ} \mathrm{C}$.

The ${ }^{177} \mathrm{Lu}$ and ${ }^{125} \mathrm{I}$ labeling yields were determined by radio-thinlayer chromatography, using instant thin-layer chromatography silica gel strips (Pall) eluted with $200 \mathrm{mM}$ ethylenediaminetetraacetic acid in $0.9 \% \mathrm{NaCl}$ and $20 \mathrm{mM}$ citric acid at $\mathrm{pH} 5.2$, respectively. The yields were imaged on a phosphor imager (FLA-7000; Fujifilm) and quantified with AIDA Image Analyzer software. Analytic radioHPLC was performed on an Agilent 1100 system equipped with a C18 Eclipse XBD column $(150 \times 4.6 \mathrm{~mm}$; particle size, $5 \mu \mathrm{m})$ and a Gabi radioactive detector (Raytest). The radiochemical purities were $95 \%$ or higher and typically at least $98 \% .{ }^{177} \mathrm{Lu}$-labeled dACPP was mixed with ${ }^{125}$ I-labeled dACPP in a $1: 1$ molar ratio.

\section{Cell Culture}

HT-1080 fibrosarcoma cells acquired from the American Type Culture Collection were maintained under standard culture conditions in Eagle's minimal essential medium (MEM) supplemented with $10 \%$ heat-inactivated fetal bovine serum (Gibco), penicillin $(100 \mathrm{U} / \mathrm{mL})$, streptomycin $(100 \mu \mathrm{g} / \mathrm{mL})$, and $2 \mathrm{mM}$ Glutamax (Gibco).

\section{In Vitro Cell Incubation with Radiolabeled ACPP Probes}

${ }^{177} \mathrm{Lu}-\mathrm{ACPP}$ was activated before cell incubation with recombinant-human MMP-2 (10 pmol) for $3 \mathrm{~h}$ in $50 \mathrm{mM}$ Tris, $200 \mathrm{mM}$ $\mathrm{NaCl}, 10 \mathrm{mM} \mathrm{CaCl}_{2}$, and $10 \mu \mathrm{M} \mathrm{ZnCl}_{2}$ at $\mathrm{pH} 7.5$, as was assessed by reversed-phase HPLC. HT-1080 cells were cultured in poly-Dlysine-coated 12-well plates. At $80 \%$ confluency, cells were washed twice with Dulbecco's PBS (Gibco) and once with serum-free medium and subsequently incubated in triplicate with $1.25 \mu \mathrm{M}{ }^{177} \mathrm{Lu}$-non-ACPP, $1.25 \mu \mathrm{M}$ uncleaved ${ }^{177} \mathrm{Lu}$-ACPP, 1.25 $\mu \mathrm{M}$ precleaved ${ }^{177} \mathrm{Lu}-\mathrm{ACPP}$, and $1.25 \mu \mathrm{M}{ }^{177} \mathrm{Lu}-\mathrm{CPP}(19.3 \mu \mathrm{L} /$ $1.25 \mathrm{nmol}$ of probe, $0.5 \mathrm{MBq}$ of $\left.{ }^{177} \mathrm{Lu}\right)$ in serum-free medium $(981$ $\mu \mathrm{L})$. After $3 \mathrm{~h}$ of incubation, cells were washed 5 times with Dulbecco's PBS and harvested by trypsination $(0.25 \%$ w/v trypsin-ethylenediaminetetraacetic acid [Gibco]). The trypsin activity was inhibited by addition of MEM, after which the cells were isolated by centrifugation (1,000 rpm, $10 \mathrm{~min}$, room temperature). Cell pellets and all wash fractions were analyzed for ${ }^{177} \mathrm{Lu}$ radioactivity (115-270 keV) by a $\gamma$-counter (Wizard 1480; PerkinElmer).

\section{HT-1080 Fibrosarcoma Model}

HT- 1080 cells at $80 \%-90 \%$ confluency were harvested by trypsination. The trypsin activity was inhibited by the addition of MEM, after which cells were isolated by centrifugation. The cells were washed once with sterile Dulbecco's PBS and concentrated to $3.0 \times 10^{7}$ cells $/ \mathrm{mL}$. Approximately $3.0 \times 10^{6} \mathrm{HT}-1080$ cells (in $100 \mu \mathrm{L}$ of sterile Dulbecco's PBS) were injected per mouse, subcutaneously on the left flank. The tumor sizes were determined by a ruler every $2 \mathrm{~d}$, and their volumes were calculated using the formula $1 / 2 \times 1 \times \mathrm{b} \times \mathrm{h}$. When tumors reached $8-30 \mathrm{~mm}^{3}$ (typically 1-2 wk after subcutaneous injection), the mice were used for in vivo studies.

\section{Biodistribution Experiments}

Biodistribution experiments were performed on tumor-bearing mice $(n=3)$ or tumor-free healthy mice $(n=4)$ by intravenous injection of ${ }^{177} \mathrm{Lu}-\mathrm{ACPP}(60 \mathrm{nmol} / 100 \mu \mathrm{L}, \sim 1.0 \mathrm{MBq}),{ }^{177} \mathrm{Lu}-$ non-ACPP $(60 \mathrm{nmol} / 100 \mu \mathrm{L}, \sim 1.0 \mathrm{MBq}),{ }^{177} \mathrm{Lu} /{ }^{125} \mathrm{I}-\mathrm{dACPP}(60$ $\mathrm{nmol} / 100 \mu \mathrm{L}, \sim 1.0 \mathrm{MBq}$ of ${ }^{177} \mathrm{Lu}$ and $\sim 0.25 \mathrm{MBq}$ of $\left.{ }^{125} \mathrm{I}\right)$, 
${ }^{177} \mathrm{Lu} /{ }^{125} \mathrm{I}$-non-dACPP $\left(60 \mathrm{nmol} / 100 \mu \mathrm{L}, \sim 1.0 \mathrm{MBq}\right.$ of ${ }^{177} \mathrm{Lu}$ and $\sim 0.25 \mathrm{MBq}$ of $\left.{ }^{125} \mathrm{I}\right)$, or ${ }^{177} \mathrm{Lu}-\mathrm{CPP}(60 \mathrm{nmol} / 100 \mu \mathrm{L}, \sim 1.0 \mathrm{MBq})$. The mice were anesthetized with isoflurane 6 or $24 \mathrm{~h}$ after intravenous injection, subjected to cardiac puncture, and sacrificed by cervical dislocation. Organs and tissues of interest were harvested and weighed, after which the radioactivity of the samples was measured in a $\gamma$-counter along with standards to determine the injected dose per gram $(\% \mathrm{ID} / \mathrm{g})$. The energy windows were set to $10-80 \mathrm{keV}$ for ${ }^{125} \mathrm{I}$ and $155-380 \mathrm{keV}$ for ${ }^{177} \mathrm{Lu}$.

\section{Blood Kinetic Measurements Plus Biodistribution Experiments}

Tumor-bearing mice $(n=3)$ were intravenously injected with ${ }^{177} \mathrm{Lu}-$ ACPP $(60 \mathrm{nmol} / 100 \mu \mathrm{L}, \sim 1.0 \mathrm{MBq}),{ }^{177} \mathrm{Lu}$-non-ACPP (60 $\mathrm{nmol} / 100 \mu \mathrm{L}, \sim 1.0 \mathrm{MBq}),{ }^{177} \mathrm{Lu} /{ }^{125} \mathrm{I}-\mathrm{dACPP}(60 \mathrm{nmol} / 100 \mu \mathrm{L}$, $\sim 1.0 \mathrm{MBq}$ of ${ }^{177} \mathrm{Lu}$ and $\sim 0.25 \mathrm{MBq}$ of $\left.{ }^{125} \mathrm{I}\right),{ }^{177} \mathrm{Lu} /{ }^{125} \mathrm{I}$-nondACPP $\left(60 \mathrm{nmol} / 100 \mu \mathrm{L}, \sim 1.0 \mathrm{MBq}\right.$ of ${ }^{177} \mathrm{Lu}$ and $\sim 0.25 \mathrm{MBq}$ of $\left.{ }^{125} \mathrm{I}\right)$, or ${ }^{177} \mathrm{Lu}-\mathrm{CPP}(60 \mathrm{nmol} / 100 \mu \mathrm{L}, \sim 1.0 \mathrm{MBq})$. At selected time points $(2,5,10$, and $30 \mathrm{~min}$ and 1 and $3 \mathrm{~h}$ ), blood samples were withdrawn from the vena saphena, weighed, and diluted to 1 $\mathrm{mL}$ with MilliQ water. The mice were anesthetized with isoflurane $24 \mathrm{~h}$ after intravenous injection, subjected to cardiac puncture, and sacrificed by cervical dislocation. Organs and tissues of interest were harvested and weighed, after which the radioactivity was measured for all samples in a $\gamma$-counter along with standards to determine the $\% \mathrm{ID} / \mathrm{g}$. The probe concentration at time $0\left(\mathrm{C}_{0}\right)$ was calculated by fitting the blood clearance curves to a 2-phase exponential decay for ACPP, non-ACPP, dACPP, and non-dACPP and to a 1-phase exponential decay for CPP. The volume of distribution per mouse was calculated using the formula $\mathrm{V}_{\mathrm{D}}=$ dose/(body weight $\left.\times \mathrm{C}_{0}\right)[\mathrm{L} / \mathrm{kg}]$.

\section{Gelatin Zymography}

Methods for gelatin zymography are described in the supplemental materials.

\section{Statistical Methods}

Quantitative data were expressed as mean \pm SD. The means of the groups were compared by the parametric Welch's $t$ test (28). Because of the relatively small sample sizes per group $(n=4-6)$, the nonparametric Mann-Whitney $U$ test was also performed. All tests were 2-tailed, and $P$ values of less than 0.05 indicate significant differences.

\section{RESULTS}

\section{In Vitro Studies}

The sensitivity of the ACPP structure toward 9 different enzymes (MMP-1, MMP-2, MMP-3, MMP-7, MMP-9, MMP-14, urokinase, plasmin, and thrombin) was studied in vitro. LC-MS analysis after $1 \mathrm{~h}$ of incubation showed that ACPP is efficiently cleaved between the glycine and leucine residue by MMP-2, MMP-9, and, to a minor extent, MMP14, whereas no ACPP cleavage was observed for the other enzymes (Fig. 2). Under similar conditions, MMP-2 was not able to cleave the negative-control peptide non-ACPP (Supplemental Fig. 2).

Next, we radiolabeled the polycationic domain of ACPP with ${ }^{177} \mathrm{Lu}$ (Supplemental Figs. 3 and 4) and set out to assess the uptake of ${ }^{177} \mathrm{Lu}-\mathrm{ACPP}$ by MMP-positive HT1080 cells. Although these cells secrete MMP-2 and

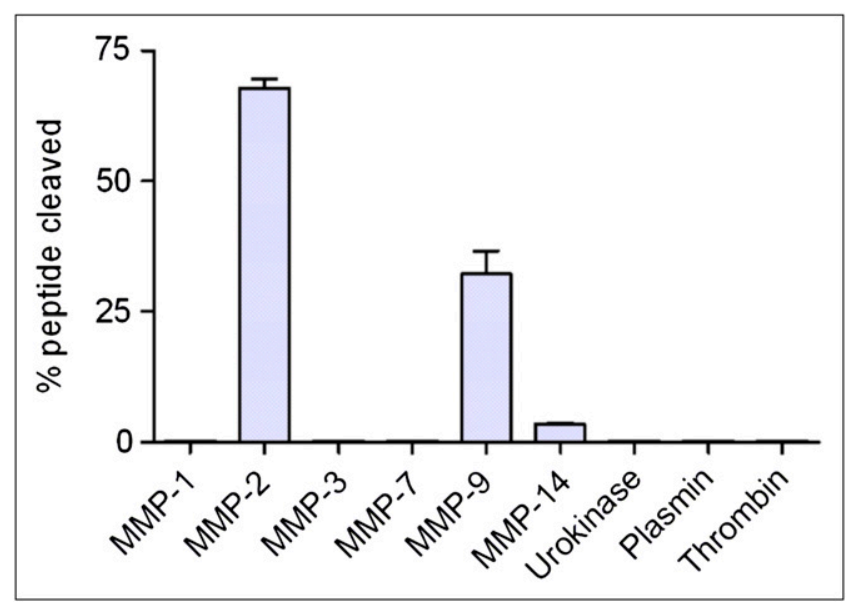

FIGURE 2. ACPP sensitivity toward 9 different enzymes in vitro, showing percentage cleaved ACPP after $1 \mathrm{~h}$ of incubation. Experiments were performed in triplicate, and data are mean \pm SD.

MMP-9, as was evidenced by gelatin zymography (Supplemental Fig. 5), it has been demonstrated that those enzymes become too diluted in 2-dimensional cell culture supernatants, resulting in minimal ACPP probe activation and insignificant uptake (22). Therefore, ${ }^{177} \mathrm{Lu}$-ACPP was precleaved with MMP-2 (resulting in $85 \%$ activation, Supplemental Fig. 6), incubated for $3 \mathrm{~h}$ at $1.25 \mu \mathrm{M}$ with HT-1080 cells, and compared with ${ }^{177} \mathrm{Lu}$-non-ACPP, uncleaved ${ }^{177} \mathrm{Lu}-$ ACPP, and ${ }^{177} \mathrm{Lu}-\mathrm{CPP}$. The cellular uptake of the activated ACPP was comparable to the uptake of the positive control, taking the $85 \%$ activation of ACPP into account, whereas uncleaved ACPP showed negligible cellular uptake (Fig. 3).

\section{In Vivo Biodistribution of ACPP and Non-ACPP and Its Dual-Isotope-Labeled Analogs in Tumor-Bearing and Healthy Mice}

Our investigations continued with in vivo biodistribution studies of the radiolabeled ACPP and the negative-control

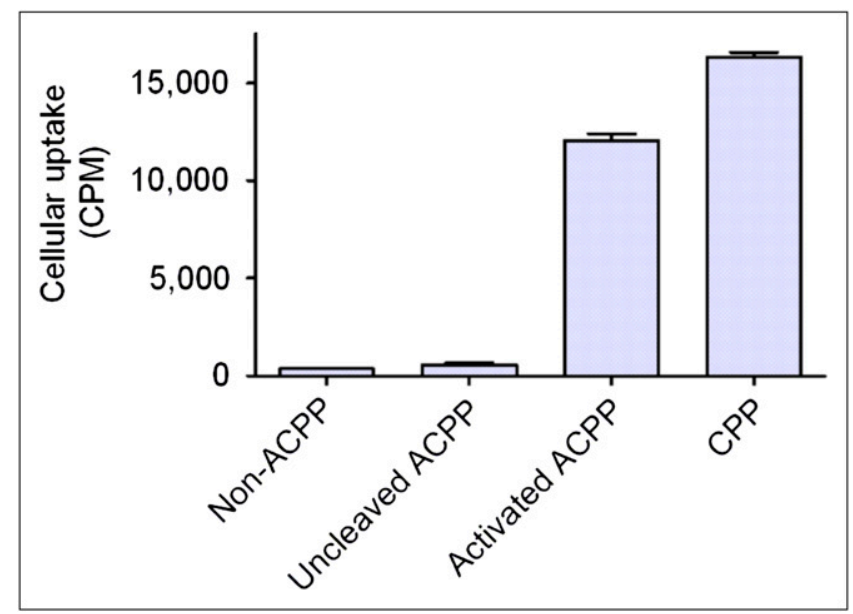

FIGURE 3. Cellular uptake of ${ }^{177} \mathrm{Lu}$-non-ACPP, uncleaved ${ }^{177} \mathrm{Lu}-$ ACPP, preactivated (for $85 \%$ ) ${ }^{177} \mathrm{Lu}-\mathrm{ACPP}$, and ${ }^{177} \mathrm{Lu}-\mathrm{CPP}$ by HT1080 fibrosarcoma cells after $3 \mathrm{~h}$ of incubation. Experiments were performed in triplicate, and data are mean \pm SD. 
peptide non-ACPP (60 nmol, intravenous injection) in MMP-2/9-positive HT-1080 tumor-bearing mice (Fig. 4; Supplemental Table 1). Table 1 shows the statistical analysis of the biodistribution data. The tumor uptake of ${ }^{177} \mathrm{Lu}$-ACPP was significantly higher compared with its accumulation in muscle and with the tumor uptake of ${ }^{177} \mathrm{Lu}$-non-ACPP after 6 and $24 \mathrm{~h}$, supporting earlier studies proposing ACPP activation by tumoral MMP-2/9 (21-23). Surprisingly, however, not only the tumor but also other tissues showed significantly higher retention of ${ }^{177} \mathrm{Lu}-\mathrm{ACPP}$ than of ${ }^{177} \mathrm{Lu}$-non-ACPP. In the muscle and heart, the relative difference between ${ }^{177} \mathrm{Lu}-$ ACPP and ${ }^{177} \mathrm{Lu}$-non-ACPP retention was even higher than that observed for tumors (Supplemental Table 1), although no MMP-2/9 activity was detected by gelatin zymography in these tissues (Supplemental Fig. 5). Furthermore, ${ }^{177} \mathrm{Lu}-$ nonACPP displayed a significantly higher tumor retention than muscle and heart retention. A high liver, spleen, and kidney retention was observed for ${ }^{177} \mathrm{Lu}-\mathrm{ACPP}$, whereas ${ }^{177} \mathrm{Lu}-$ nonACPP accumulated mainly in the kidneys, indicating that the probes are excreted via different pathways. As CPPs have been reported to mainly distribute to the liver $(22,29)$, the altered biodistribution may have been caused by enzymatic conversion of ${ }^{177} \mathrm{Lu}$-ACPP into ${ }^{177} \mathrm{Lu}-\mathrm{CPP}$. The biodistribution data obtained with ACPP do not, however, allow discrimination between retention of uncleaved ACPP and the MMP cleavage product CPP. In principle, the differences found in the tissue accumulation of ACPP and non-ACPP could originate from aspecific accumulation instead of tumoral MMP-related activation. To address this open question and to unravel the activation process of ACPP (i.e., does ACPP activation takes place and, if so, where?), we developed dual-isotope-radiolabeled analogs (dACPPs) (Fig. 1B), in which the polycationic CPP and polyanionic peptide were labeled with the orthogonal radioisotopes ${ }^{177} \mathrm{Lu}$ (energy of $\gamma$-ray emitted by isotope $\left.\left[\mathrm{E}_{\gamma}\right]=208 \mathrm{keV}\right)$ and ${ }^{125} \mathrm{I}\left(\mathrm{E}_{\gamma}=35\right.$ $\mathrm{keV}$ ), respectively (Supplemental Figs. 3 and 4). A large ratio of ${ }^{177} \mathrm{Lu}$ over ${ }^{125} \mathrm{I}$ would indicate cleavage of the probe and subsequent retention of the ${ }^{177} \mathrm{Lu}$-radiolabeled CPP. The in vivo biodistribution of the dual-isotope probe ${ }^{177} \mathrm{Lu} /{ }^{125} \mathrm{I}-$ dACPP $24 \mathrm{~h}$ after intravenous injection showed an approximately 10 - to 50 -fold-higher retention of ${ }^{177} \mathrm{Lu}$ than ${ }^{125} \mathrm{I}$ in the tumor, muscle, heart, lung, and spleen (Fig. 5A; Supple-

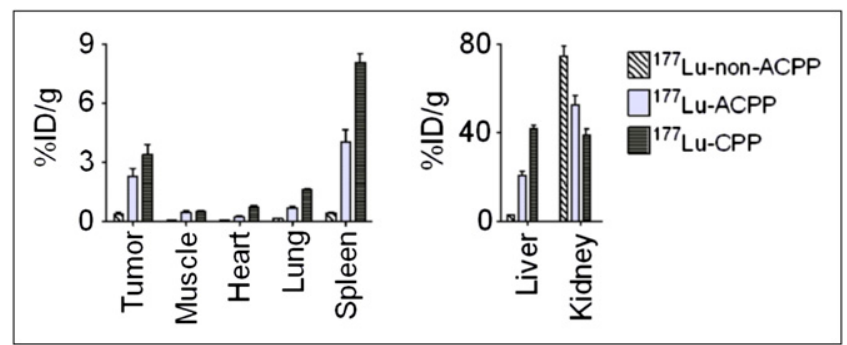

FIGURE 4. Comparison of in vivo biodistribution of ${ }^{177} \mathrm{Lu}$-non-ACPP, ${ }^{177} \mathrm{Lu}-\mathrm{ACPP}$, and ${ }^{177} \mathrm{Lu}-\mathrm{CPP}$ in tumor-bearing mice. Sixty nanomoles of ${ }^{177}$ Lu-non-ACPP, ${ }^{177}$ Lu-ACPP, and ${ }^{177}$ Lu-CPP were intravenously injected in tumor-bearing mice $(n=6)$. Data are mean $\% \mathrm{ID} / \mathrm{g} \pm \mathrm{SD}$. mental Table 3). For ${ }^{177} \mathrm{Lu} /{ }^{125} \mathrm{I}-$ non-dACPP, the tissue retention of ${ }^{177} \mathrm{Lu}$ was only slightly higher-that is, approximately 2- to 3-fold-than that of ${ }^{125}$ I (Fig. 5B). Furthermore, the biodistribution of ${ }^{177} \mathrm{Lu} /{ }^{125} \mathrm{I}-\mathrm{dACPP}$ showed a high accumulation of ${ }^{177} \mathrm{Lu}$ in the liver, whereas ${ }^{125}$ I retention was minimal. An in vivo biodistribution study of ${ }^{177} \mathrm{Lu} /{ }^{125} \mathrm{I}-\mathrm{dACPP}$ in tumor-free healthy mice was also performed, which showed the same 10- to 50-fold-higher retention levels of ${ }^{177} \mathrm{Lu}$ relative to ${ }^{125} \mathrm{I}$ in various tissues as was observed in tumor-bearing mice (Fig. 5C; Supplemental Table 3), suggesting that the dACPP activation is not caused by tumorassociated MMP-2/9.

\section{In Vivo Biodistribution of Radiolabeled CPP}

The in vivo biodistribution of ${ }^{177} \mathrm{Lu}-\mathrm{CPP}$ (Fig. 4; Supplemental Table 1), the activated CPP domain of ACPP serving as a positive control, revealed significantly higher tumor retention levels than muscle and heart retention. Comparison of the tumor-to-tissue ratios for ${ }^{177} \mathrm{Lu}-\mathrm{ACPP}$ and ${ }^{177}$ Lu-CPP showed no significant differences (Fig. 6; Table 1; Supplemental Table 2), indicating that ACPP was most likely activated in the vascular compartment.

\section{Blood Kinetic Profiles}

${ }^{177} \mathrm{Lu} /{ }^{125} \mathrm{I}-\mathrm{dACPP}$ showed a faster blood clearance of ${ }^{177} \mathrm{Lu}$ than ${ }^{125} \mathrm{I}$ (Fig. 7B), pointing to dACPP activation and subsequent tissue trapping of ${ }^{177} \mathrm{Lu}-\mathrm{CPP}$, whereas comparable blood clearance rates were observed for ${ }^{177} \mathrm{Lu}$ and ${ }^{125} \mathrm{I}$ for mice injected with ${ }^{177} \mathrm{Lu} /{ }^{125} \mathrm{I}$-non-ACPP (Fig. 7C). We observed a 30- and 10-fold-higher blood concentration for ${ }^{177} \mathrm{Lu}-\mathrm{CPP}$ (Supplemental Fig. 7) and ${ }^{177} \mathrm{Lu}-\mathrm{ACPP}$, respectively (Fig. 7A), than for ${ }^{177} \mathrm{Lu}$-non-ACPP at $3 \mathrm{~h}$ after injection, indicating the presence of activated CPP in blood for ${ }^{177} \mathrm{Lu}-\mathrm{ACPP}$ at this time point. After $6 \mathrm{~h}$, both ACPP

TABLE 1

Statistical Analysis of Biodistribution Data Comparing Means of ${ }^{177} \mathrm{Lu}-\mathrm{ACPP}$ and ${ }^{177} \mathrm{Lu}-\mathrm{non}-\mathrm{ACPP}$ and of Tumorto-Tissue Ratios Comparing ${ }^{177} \mathrm{Lu}-\mathrm{ACPP}$ and ${ }^{177} \mathrm{Lu}-\mathrm{CPP}$

\begin{tabular}{lll}
\multicolumn{1}{c}{ Probe } & $\begin{array}{c}\text { Welch's } \\
t \text { test }\end{array}$ & $\begin{array}{c}\text { Mann-Whitney } \\
U \text { test }\end{array}$ \\
\hline $\begin{array}{l}\text { ACPP vs. non-ACPP } \\
\text { Tumor }\end{array}$ & 0.0158 & 0.0022 \\
$\quad$ Muscle & 0.0036 & 0.0022 \\
$\quad$ Heart & 0.0016 & 0.0022 \\
ACPP & & \\
$\quad$ Tumor vs. muscle & 0.0114 & 0.0022 \\
$\quad$ Tumor vs. heart & 0.0068 & 0.0022 \\
Non-ACPP & & \\
$\quad$ Tumor vs. muscle & 0.0036 & 0.0022 \\
$\quad$ Tumor vs. heart & 0.0034 & 0.0022 \\
ACPP vs. CPP & & \\
$\quad$ Tumor-to-muscle ratio & 0.3941 & 0.2403 \\
$\quad$ Tumor-to-heart ratio & 0.0840 & 0.0931 \\
$\quad$ Tumor-to-lung ratio & 0.1379 & 0.1320 \\
$\quad$ Tumor-to-spleen ratio & 0.2384 & 0.3095 \\
\hline
\end{tabular}




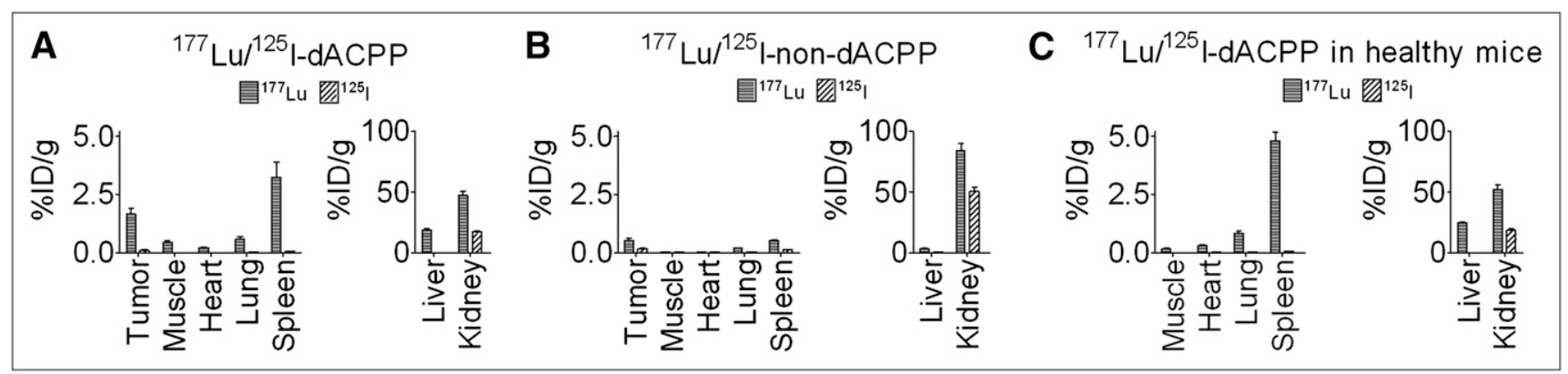

FIGURE 5. Comparison of in vivo biodistribution of ${ }^{177} \mathrm{Lu} /{ }^{125} \mathrm{I}-\mathrm{dACPP}(60 \mathrm{nmol}, n=6)(\mathrm{A})$ and ${ }^{177} \mathrm{Lu} /{ }^{125} \mathrm{I}-\mathrm{non}-\mathrm{dACPP}(60 \mathrm{nmol}, n=6)(\mathrm{B})$ in tumor-bearing mice and ${ }^{177} \mathrm{Lu} /{ }^{125} \mathrm{I}-\mathrm{dACPP}(60 \mathrm{nmol}, n=4)(\mathrm{C})$ in tumor-free healthy mice. Data are presented as mean $\% \mathrm{ID} / \mathrm{g} \pm \mathrm{SD}$.

and non-ACPP were essentially cleared from the circulation (Supplemental Table 1).

\section{Determination of Volume of Distribution $\left(V_{D}\right)$}

The $\mathrm{V}_{\mathrm{D}}$ calculated from the blood clearance measurements is in the range of $0.27<\mathrm{V}_{\mathrm{D}}<0.36 \mathrm{~L} / \mathrm{kg}$ of body weight $\left(\mathrm{V}_{\mathrm{D}}\right.$ values in $\mathrm{L} / \mathrm{kg}$ are $0.36 \pm 0.19$ for ACPP, $0.32 \pm 0.05$ for non-ACPP, $0.27 \pm 0.17$ for dACPP, and $0.29 \pm 0.08$ for non-dACPP). The blood clearance measurements point toward a rapid distribution of these probes throughout the extracellular fluids in the whole body, without cell membrane crossing but with some binding to compounds and cell surfaces in the extracellular, extravascular space (30). The $\mathrm{V}_{\mathrm{D}}$ for ${ }^{177} \mathrm{Lu}-\mathrm{CPP}$ was found to be 4 -foldhigher $(1.28 \pm 0.21 \mathrm{~L} / \mathrm{kg})$, suggesting that a significant amount of the highly positively charged polypeptide directly binds to cells in the extravascular, extracellular space and to endothelial cells in the vascular space. In this respect, CPP will probably have a high tendency to bind to circulating cells as well, which would explain the relatively high blood levels of CPP observed at later time points (Supplemental Fig. 7). Alternatively, a slow desorption of the polycationic peptide and subsequent transport back into the circulation is a reasonable explanation for the observed prolonged blood clearance profile (22).

\section{DISCUSSION}

The use of activatable cell-penetrating imaging probes has been advocated as a promising general strategy for the in vivo imaging of proteolytic activity, in particular in tumors $(21,31)$. Several recent reports have asserted that tumors can be visualized via optical imaging and MRI of MMP-2/9 activity using ACPPs (21-25). An analogous radiolabeled ACPP probe for PET or SPECT would allow clinical translation to sensitive whole-body diagnostic imaging while avoiding potential toxicity risks associated with gadolinium uptake and retention in cells and organs. Therefore, we set our sights on the development of radiolabeled ACPPs consisting of an MMP-2/9-sensitive peptide linker. In accordance with the results for a Cy-5-conjugated MMP-2/9-cleavable ACPP (21,22), we showed that the radiolabeled ACPPs can efficiently be activated by MMP2/9 in vitro (Figs. 2 and 3). The in vivo biodistribution of a
${ }^{177} \mathrm{Lu}$-radiolabeled ACPP and a negative-control non-ACPP containing a scrambled linker was assessed in mice bearing MMP-2/9-positive tumors (Fig. 4; Supplemental Tables 1 and 2). We found for the ACPP a high uptake in the tumor, compared with muscle or heart, but an even higher uptake in the spleen, liver, and kidney. For the tumor, ACPP exhibited a 6-fold-higher retention than non-ACPP-a slightly higher retention than reported by Jiang et al. (21), Aguilera et al. (22), and Olson et al. (23) for their optical probes.

At a first glance, this higher retention seems to support ACPP sensitivity toward tumoral MMP-2/9, but surprisingly, the retention ratios for ACPP over non-ACPP were higher in many tissues than the ratio found for the tumor. For example, the ACPP retention in muscle is 12-fold higher than non-ACPP, despite the fact that MMP-2/9 activity in muscle was not detected by gelatin zymography (Supplemental Fig. 5). Dual-isotope-labeled ACPPs, in which the polycationic CPP was labeled with ${ }^{177} \mathrm{Lu}$ and the polyanionic domain was labeled with ${ }^{125} \mathrm{I}$, revealed ${ }^{177} \mathrm{Lu}$-to- ${ }^{125}$ I tissue ratios of 10:50 in tumor, muscle, heart, lung, and spleen, indicating that ACPP had been activated and subsequently retained in all tissues as ${ }^{177} \mathrm{Lu}-\mathrm{CPP}$ (Fig.

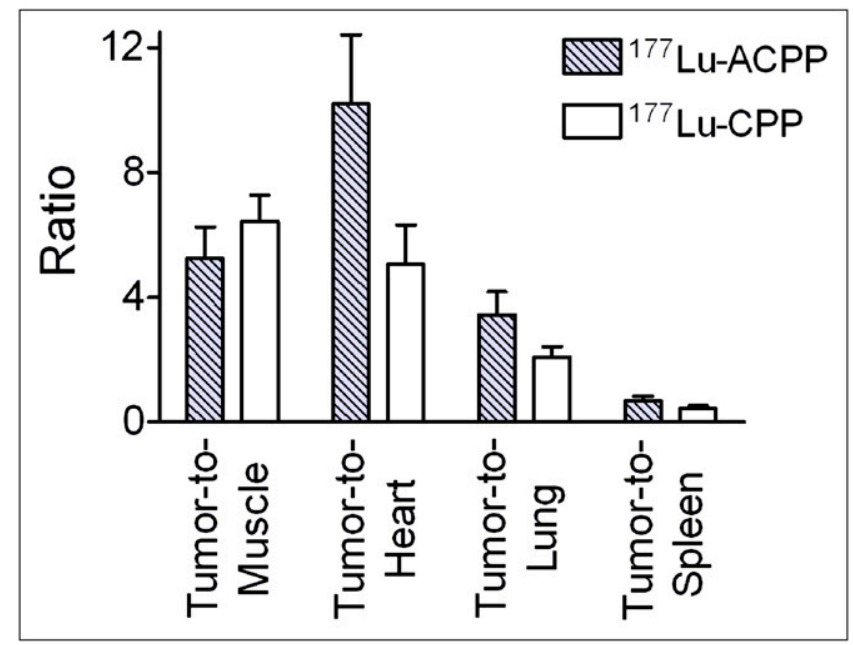

FIGURE 6. Tumor-to-tissue ratios for $60 \mathrm{nmol}$ of ${ }^{177} \mathrm{Lu}$-ACPP (gray bars) and $60 \mathrm{nmol}$ of ${ }^{177} \mathrm{Lu}-\mathrm{CPP} 24 \mathrm{~h}$ after injection $(n=6)$. Data are mean $\pm \mathrm{SD}$. 


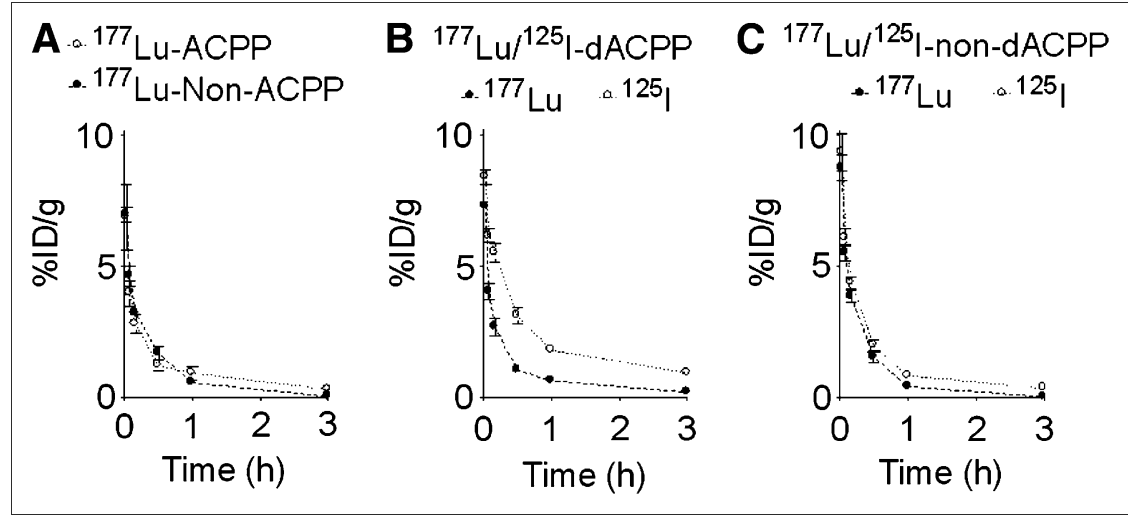

FIGURE 7. Blood kinetic profiles of $60 \mathrm{nmol}$ of ${ }^{177} \mathrm{Lu}-\mathrm{ACPP}(\mathrm{O})$ and ${ }^{177} \mathrm{Lu}-\mathrm{non}-\mathrm{ACPP}(\mathbf{\bullet})$ (A), ${ }^{177} \mathrm{Lu} /{ }^{125} \mathrm{I}-\mathrm{dACPP}(\mathrm{B})$, and ${ }^{177} \mathrm{Lu} /{ }^{125} \mathrm{I}-\mathrm{non}-$ dACPP (C) in tumor-bearing mice $(n=3)$. Data are mean $\% \mathrm{ID} / \mathrm{g} \pm \mathrm{SD}$.
5; Supplemental Table 3). Similar ${ }^{177}$ Lu-to- ${ }^{125}$ I ratios were observed in muscle, heart, lung, and spleen when dACPP was administrated to healthy mice. The negative control, on the other hand, showed modest ${ }^{177} \mathrm{Lu}$-to- ${ }^{125}$ I tissue ratios of 2 to 3 , possibly caused by activation by aspecific proteolytic degradation of the linker around one of the flexible glycine residues. The iodinated probes were not subject to significant dehalogenation, as evidenced by the low amount of ${ }^{125}$ I measured in thyroids and the stomach (Supplemental Table 3).

The biodistribution and blood clearance experiments for the various probes compellingly show that the used ACPP is taken up and retained in all tissues in its activated form, even in the absence of an MMP-expressing tumor (Fig. 5C). These findings do not support tumor-associated MMP-2/9 cleavage of ACPP as the main mechanism for ACPP activation and subsequent tumor accumulation. Instead, the higher retention of the activated ACPP in tumor than in muscle is most likely due to tissue aspecific ACPP activation, resulting in increased accumulation of the activated probe in the tumor promoted by the enhanced permeability and retention effect in combination with high vascularization (32). Further evidence for this assertion comes from the similar biodistribution profiles observed for ${ }^{177} \mathrm{Lu}-$ ACPP and the positive-control ${ }^{177} \mathrm{Lu}-\mathrm{CPP}$ (Fig. 6). Passive uptake due to tumor leakiness will likely occur for any probe with a high free $\mathrm{V}_{\mathrm{D}}$, including our negative-control peptide non-ACPP, explaining the significantly higher tumor uptake than muscle uptake of non-ACPP and the smaller relative difference in uptake between ACPP and non-ACPP in tumor, compared with muscle.

Interestingly, it was recently demonstrated that tumor retention of nanoparticles by the enhanced permeability and retention effect can be further increased by MMP-2/9-sensitive ACPP functionalization of the nanoparticles (24). This study also showed that significantly higher muscle uptake was obtained for MMP-2-sensitive ACPP-labeled nanoparticles than for non-ACPP-labeled nanoparticles_-a finding consistent with an activation of the nanoparticles in the vascular system and subsequent tissue aspecific uptake. The tumorto-muscle ratio for this MMP activatable nanoparticle was approximately 6 , slightly higher than observed for the low- molecular-weight MMP activatable peptides $(23,24)$, indicating that the enhanced permeability and retention effect may play out favorably for larger activatable probes.

\section{CONCLUSION}

We have reported the first in vivo studies exploring the use of radiolabeled ACPPs for the detection of MMP activity in tumors. Activation of the radiolabeled ACPP indeed resulted in a strong enhancement of tumor retention in vivo, showing that the concept of ACPPs can be translated to nuclear applications. However, dual-isotope-labeled ACPPs and control experiments in healthy and tumor-bearing mice revealed that the activation of ACPP was tumorindependent. Most likely, probe activation occurred already in the vasculature, followed by aspecific tumor uptake. Therefore, several challenges need to be addressed to achieve clinical translation of ACPPs. First, the proteasesensitive linker should be carefully chosen to prevent aspecific cleavage. Second, highly specific accumulation in the tissue of interest may be achieved by ACPPs that are exclusively sensitive to cell membrane-bound enzymes that do not shed into the vasculature, thereby avoiding ACPP activation in the blood.

\section{ACKNOWLEDGMENTS}

We thank Maarten Merkx (Eindhoven University of Technology) for providing useful discussions and access to the peptide synthesizer, Iris Verel and Raffaella Rossin (Philips Research) for providing useful discussions, Caren van Kammen and Carlijn van Helvert (University Hospital Maastricht) for carrying out subcutaneous and intravenous injections, and Monique Berben (Philips Research) for performing the biodistribution studies. This research was performed within the framework of the CTMM (Center for Translational Molecular Medicine [www.ctmm.nl]) project TRIUMPH (grant 01C-103) and supported by the Netherlands Heart Foundation.

\section{REFERENCES}

1. Davidson B, Goldberg I, Kopolovic J, et al. MMP-2 and TIMP-2 expression correlates with poor prognosis in cervical carcinoma: a clinicopathologic study 
using immunohistochemistry and mRNA in situ hybridization. Gynecol Oncol. 1999;73:372-382.

2. Kanayama H, Yokota K, Kurokawa Y, Murakami Y, Nishitani M, Kagawa S. Prognostic values of matrix metalloproteinase-2 and tissue inhibitor of metalloproteinase-2 expression in bladder cancer. Cancer. 1998;82:1359-1366.

3. Sakakibara M, Koizumi S, Saikawa Y, et al. Membrane-type matrix metalloproteinase-1 expression and activation of gelatinase A as prognostic markers in advanced pediatric neuroblastoma. Cancer. 1999;85:231-239.

4. Jezierska A, Motyl T. Matrix metalloproteinase-2 involvement in breast cancer progression: a mini-review. Med Sci Monit. 2009;15:RA32-RA40.

5. Pieper-Furst U, Kleuser U, Stocklein WF, Warsinke A, Scheller FW. Detection of subpicomolar concentrations of human matrix metalloproteinase- 2 by an optical biosensor. Anal Biochem. 2004;332:160-167.

6. Ardito CM, Briggs CD, Crawford HC. Targeting of extracellular proteases required for the progression of pancreatic cancer. Expert Opin Ther Targets. 2008;12:605-619.

7. Faust A, Waschkau B, Waldeck J, et al. Synthesis and evaluation of a novel hydroxamate based fluorescent photoprobe for imaging of matrix metalloproteinases. Bioconjug Chem. 2009;20:904-912.

8. Park B-H, Chang Y, Lee Y-J, et al. Targeting of membrane type1-matrix metalloproteinase (MT1-MMP) using superparamagnetic nanoparticles in human liver cancer cells. Colloids Surface A. 2008;313-314:647-650.

9. Schäfers M, Schober O, Hermann S. Matrix-metalloproteinases as imaging targets for inflammatory activity in atherosclerotic plaques. J Nucl Med. 2010;51: 663-666.

10. Breyholz HJ, Wagner S, Faust A, et al. Radiofluorinated pyrimidine-2,4,6-triones as molecular probes for noninvasive MMP-targeted imaging. ChemMedChem. 2010;5:777-789.

11. Wagner S, Breyholz HJ, Holtke C, et al. A new ${ }^{18} \mathrm{~F}$-labelled derivative of the MMP inhibitor CGS 27023A for PET: radiosynthesis and initial small-animal PET studies. Appl Radiat Isot. 2009;67:606-610.

12. Ohshima S, Petrov A, Fujimoto S, et al. Molecular imaging of matrix metalloproteinase expression in atherosclerotic plaques of mice deficient in apolipoprotein e or low-density-lipoprotein receptor. J Nucl Med. 2009;50:612-617.

13. Law B, Tung CH. Proteolysis: a biological process adapted in drug delivery, therapy, and imaging. Bioconjug Chem. 2009;20:1683-1695.

14. Mahmood U, Weissleder R. Near-infrared optical imaging of proteases in cancer. Mol Cancer Ther. 2003;2:489-496.

15. McIntyre JO, Fingleton B, Wells KS, et al. Development of a novel fluorogenic proteolytic beacon for in vivo detection and imaging of tumour-associated matrix metalloproteinase-7 activity. Biochem J. 2004;377:617-628.

16. Lee S, Park K, Lee SY, et al. Dark quenched matrix metalloproteinase fluorogenic probe for imaging osteoarthritis development in vivo. Bioconjug Chem. 2008;19:1743-1747.
17. Elegbede AI, Banerjee J, Hanson AJ, et al. Mechanistic studies of the triggered release of liposomal contents by matrix metalloproteinase-9. J Am Chem Soc. 2008; 130:10633-10642.

18. Ouyang M, Lu S, Li XY, et al. Visualization of polarized membrane type 1 matrix metalloproteinase activity in live cells by fluorescence resonance energy transfer imaging. J Biol Chem. 2008;283:17740-17748.

19. Lebel R, Jastrzebska B, Therriault H, et al. Novel solubility-switchable MRI agent allows the noninvasive detection of matrix metalloproteinase2 activity in vivo in a mouse model. Magn Reson Med. 2008;60:10561065.

20. Zhao T, Harada H, Teramura Y, et al. A novel strategy to tag matrix metalloproteinases-positive cells for in vivo imaging of invasive and metastatic activity of tumor cells. J Control Release. 2010;144:109-114.

21. Jiang T, Olson ES, Nguyen QT, Roy M, Jennings PA, Tsien RY. Tumor imaging by means of proteolytic activation of cell-penetrating peptides. Proc Nat Acad Sci USA. 2004;101:17867-17872.

22. Aguilera TA, Olson ES, Timmers MM, Jiang T, Tsien RY. Systemic in vivo distribution of activatable cell penetrating peptides is superior to that of cell penetrating peptides. Integr Biol (Camb). 2009;1:371-381.

23. Olson ES, Aguilera TA, Jiang T, et al. In vivo characterization of activatable cell penetrating peptides for targeting protease activity in cancer. Integr Biol (Camb). 2009; 1:382-393.

24. Olson ES, Jiang T, Aguilera TA, et al. Activatable cell penetrating peptides linked to nanoparticles as dual probes for in vivo fluorescence and MR imaging of proteases. Proc Nat Acad Sci USA. 2010;107:4311-4316.

25. Nguyen QT, Olson ES, Aguilera TA, et al. Surgery with molecular fluorescence imaging using activatable cell-penetrating peptides decreases residual cancer and improves survival. Proc Nat Acad Sci USA. 2010;107:4317-4322.

26. Watkins GA, Jones EF, Scott Shell M, et al. Development of an optimized activatable MMP-14 targeted SPECT imaging probe. Bioorg Med Chem. 2009; 17:653-659.

27. Guide for the Care and Use of Laboratory Animals. Washington, DC: Government Printing Office; 1985. NIH publication 86-23.

28. Ruxton GD. The unequal variance t-test is an underused alternative to Student's t-test and the Mann-Whitney U test. Behav Ecol. 2006;17:688-690.

29. Lee HJ, Pardridge WM. Pharmacokinetics and delivery of tat and tat-protein conjugates to tissues in vivo. Bioconjug Chem. 2001;12:995-999.

30. Durbin PW, Jeung N, Kullgren B, Clemons GK. Gross composition and plasma and extracellular water volumes of tissues of a reference mouse. Health Phys. 1992;63:427-442.

31. Goun EA, Shinde R, Dehnert KW, et al. Intracellular cargo delivery by an octaarginine transporter adapted to target prostate cancer cells through cell surface protease activation. Bioconjug Chem. 2006;17:787-796.

32. Duncan R. The dawning era of polymer therapeutics. Nat Rev Drug Discov. 2003;2:347-360. 